\title{
Comparison Between Phenotypic Confirmatory Test \& Double Disc Synergy Test in Detection of Extended Spectrum $\beta$-Lactamases Producers Among Gram-Negative Bacilli
}

\author{
Abu Hena Md Saiful Karim Chowdhury ${ }^{1 *}$ \\ Sukumar Nandi ${ }^{2}$ \\ Mahbubur Rahman ${ }^{3}$ \\ A S M Ashanul Karim ${ }^{4}$ \\ Syeda Shanoor Hasina Mamtaz \\ Nura Nasrin Rowshan Ara ${ }^{6}$ \\ Sabrina Sultana ${ }^{1}$ \\ ${ }^{1}$ Department of Microbiology \\ Chittagong Medical College \\ Chittagong, Bangladesh. \\ ${ }^{2}$ Department of Microbiology \\ Abdul Malek Ukil Medical College \\ Noakhali, Bangladesh. \\ ${ }^{3}$ Department of Microbiology \\ National Hospital (Pvt) Ltd \\ Chittagong, Bangladesh. \\ ${ }^{4}$ Department of Medicine \\ University of Science \& Technology Chittagong (USTC) \\ Chittagong, Bangladesh. \\ ${ }^{5}$ Department of Pediatrics \\ Red Crescent Maternity Hospita \\ Chittagong, Bangladesh. \\ ${ }^{6}$ Department of Microbiology \\ University of Science \& Technology Chittagong (USTC) \\ Chittagong, Bangladesh.
}

${ }^{*}$ Correspondence to:

Abu Hena Md Saiful Karim Chowdhury

Lecturer

Department of Microbiology

Chittagong Medical College

Chittagong, Bangladesh.

Mobile:+8801819636883

E-mail:drsaifulkarim@yahoo.com

www.banglajol.info/index.php/CMOSHMC

\begin{abstract}
Background: Extended-Spectrum $\beta$-Lactamases (ESBLs) producing bacteria are increasing in number and causing more severe infections because of their continuous mutation and multidrug resistance property which make its treatment difficult. Thus reliable, sensitive and low cost method to detect ESBLs producers, therefore, is of major interest. The present study was undertaken to compare the sensitivity between double disc synergy test \& phenotypic confirmatory test to detect ESBLs producing bacteria. Methods: All the isolates were identified by standard procedure of identification \& isolated gram-negative bacteria initially screened by Minimum Inhibitory Concentration (MIC) ESBLs breakpoints. Then suspected ESBLs producers are confirmed by double disc synergy test \& phenotypic confirmatory test. Results: In the present study, total $176(74.89 \%)$ bacterial strains were isolated from 235 samples of wound swab \& pus, and urine. Among the isolates, 150(85.23\%) were gram-negative and $26(14.77 \%)$ were gram-positive bacteria. The gram-negative bacteria were screened for suspected ESBLs \& then subjected to confirmatory test where Phenotypic Confirmatory Test (PCT) detected 89(62.68\%) and Double Disc Synergy Test (DDST) detected 74(52.11\%) ESBL producers. So $15(10.57 \%)$ isolates were missed by double disc synergy test. In this study, we determined sensitivity, specificity, positive predictive value \& negative predictive value of Phenotypic Confirmatory Test (PCT) were 100\%, 77.9\%, 83.1\% \& 100\% respectively and those of Double Disc Synergy Test (DDST) were 83.1\%, 100\%, 100\%, and $77.9 \%$ respectively. Conclusion: Between these two tests, phenotypic confirmatory test found to be more sensitive procedure than double disc synergy test for the detection of ESBLs producing organisms.
\end{abstract}

Key words : Extended-spectrum $\beta$-lactamases; Minimum inhibitory concentration; Phenotypic confirmatory test; Double disc synergy test.

\section{INTRODUCTION}

Extended-Spectrum $\beta$-Lactamases (ESBLs) producing bacteria are becoming a major threat for patients in the hospital, long-term care facilities and community. Inappropriate antibiotic selection in infections caused by these organisms is associated with treatment failures, poor clinical outcomes, increased mortality and longer hospital stays ${ }^{1}$.

Extended-Spectrum $\beta$-Lactamases producing bacteria produce Extended-Spectrum $\beta$-Lactamase (ESBL) enzymes that mediate resistance to extended spectrum (Third generation) cephalosporins (e.g. Ceftazidime, cefotaxime, ceftrixone etc.) and monobactams (e.g. Aztreonam) but do not affect cephamycins (e.g. Cefoxitin and cefotatan) or carbapenems (e.g. meropenem or imipenem) and are inhibited by $\beta$ Lactamase inhibitors such as clavulanate, sulbactam and tazobactam ${ }^{2,3,4}$. ESBLs have been found in a wide range of gram-negative rods. Klebsiella pneumoniae seems to remain the major ESBLs producer. Another very important organism is 
Escherichia coli ${ }^{2}$. Other organisms reported to harbour ESBLs include Enterobacter species, Salmonella species, Morganella morganii, Proteus mirabilis, Serratia marcescens and Pseudomonas aeruginosa ${ }^{4,5,6}$. ESBLs have spread threateningly in many regions of the world and they presently comprise over 300 variants. The widespread use of the third generation cephalosporins and aztreonam is believed to be the major cause of the mutations in these enzymes, which has led to the emergence of the ESBLs ${ }^{1}$.

ESBL-mediated resistance is not always detectable in routine susceptibility tests. The inability of the clinical laboratory to accurately detect and report ESBLs has resulted in avoidable therapeutic failures in patients, and outbreaks of multi-drug resistant gram-negative bacterial pathogens. This study was undertaken to compare the sensitivity between double disc synergy test \& phenotypic confirmatory test to detect ESBLs producing bacteria.

\section{MATERIALS AND METHODS}

This Cross Sectional study was carried out in the Department of Microbiology, Chittagong Medical College, during the period of June 2008 to May 2009. Total 235 samples (Wound swab, pus \& urine) were collected after taking informed written consent from both sexes and different age groups patients of indoor and outpatient department of Chittagong Medical College Hospital.

Inclusion Criteria: The following categories of patients were included in this study i) Patients with infected wound ii) Infected burn patients iii) Patients with clinical signs/symptoms of urinary tract infection.

Exclusion Criteria: Pus cell $<10 / \mathrm{HPF}$ in a centrifuged urine sample ${ }^{7}$.

\section{Laboratory Procedure}

After collecting samples under all aseptic precautions, wound swabs \& pus were inoculated in Blood agar and MacConkey agar media and urine samples were inoculated in Cystine Lactose Electrolyte Deficient (CLED) agar media by calibrated wire loop $(0.01 \mathrm{ml})$. Identification of organisms were done as per standard laboratory methods of identification.

\section{Screening for ESBL producers by dilution method}

Agar dilution method: The screening for ESBL producers was done by agar dilution method as was recommended by Clinical Laboratories Standard Institute (CLSI). Any of the isolated organisms found to be grown at this stated screening antibiotics concentration (That is, MIC of the ceftriaxone, ceftazidime and cefotaxime $\geq 2 \mu \mathrm{g} / \mathrm{ml}$ ) according to CLSI, 2007 was considered as possible ESBL producers and spelled for the confirmatory tests. The use of more than one antimicrobial agent for screening improves the sensitivity of detection ${ }^{8}$.

\section{Detection of ESBLs by the confirmatory tests}

Phenotypic confirmatory test: Confirmation of the ESBL producing isolates was done by the phenotypic confirmatory test according to CLSI recommendation. In this test, third generation cephalosporin i.e. ceftazidime $(30 \mu \mathrm{g})$ and cefotaxime $(30 \mu \mathrm{g})$ disc alone and in combination with clavulanic acid $(10 \mu \mathrm{g})$ were used. Ceftazidime, cefotaxime discs were placed on one side and ceftazidime, cefotaxime discs combined with clavulanic acid $(30 / 10 \mu \mathrm{g})$ were placed on other side of the inoculated plate. After overnight incubation at $37^{\circ} \mathrm{C}$, diameter of zone of inhibition was measured. A $5 \mathrm{~mm}$ or more increases in diameter of zone of inhibition for ceftazidime and cefotaxime tested in combination with clavulanic acid versus its zone when ceftazidime and cefotaxime tested alone confirms an ESBLs producing organism ${ }^{8}$.

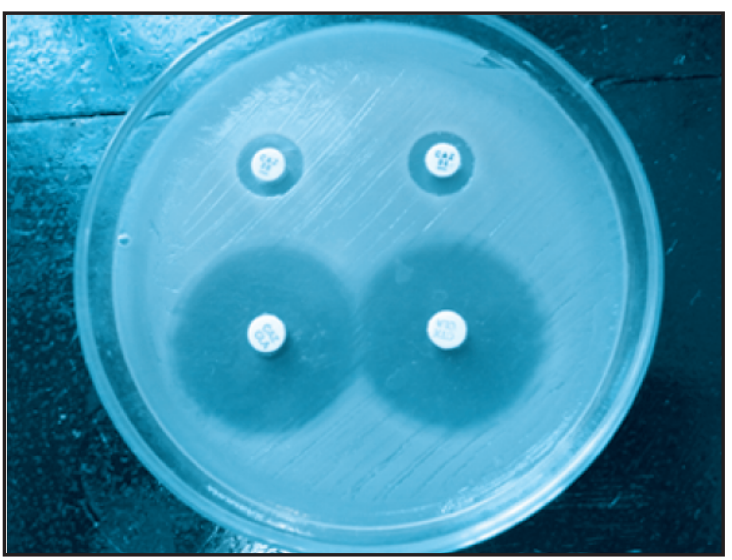

Figure 1 : Phenotypic Confirmatory Test (PCT).

Double disc synergy test/disc approximation method

By this method, synergy between a disc of augmentin (Amoxycillin and clavulanic acid) and third generation cephalosporins was detected. The clavulanate in augmentin disc diffuses through the agar and inhibits the -lactamases surrounding third generation cephalosporin disc. Discs containing $30 \mu \mathrm{g}$ of ceftazidime, cefotaxime and ceftriaxone were placed over inoculated Mueller-Hinton agar plates $20 \mathrm{~mm}$ apart from centrally placed amoxicillin-clavulanic acid disc $(20 / 10 \mu \mathrm{g})$. Following overnight incubation at $37^{\circ} \mathrm{C}$, diameter of zone of inhibition was measured. Extension of the edge of the inhibition zone of ceftazidime, cefotaxime and ceftriaxone disc on the side exposed to the disc containing amoxicillinclavulanic acid was positive for $\mathrm{ESBL}^{9}$.

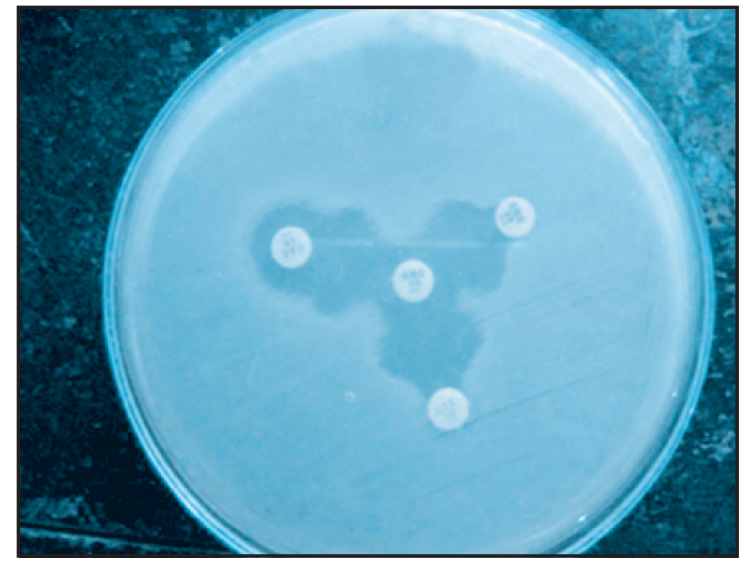

Figure 2 : Double Disc Synergy (DDST). 


\section{RESULTS}

A total 235 samples were studied, of which 115 were wound swab \& pus, and 120 were urine samples. $176(74.89 \%)$ bacterial strains were isolated, of which $105(91.30 \%)$ isolated from wound swab \& pus, and 71(59.17\%) from urine samples.

Table 1 : Distribution of isolated bacteria from different samples $(n=235)$.

\begin{tabular}{lccc} 
Samples & $\begin{array}{c}\text { Number of } \\
\text { samples studied }\end{array}$ & $\begin{array}{c}\text { Number of } \\
\text { isolated bacteria }\end{array}$ & $\begin{array}{c}\text { Percentage } \\
(\%)\end{array}$ \\
Wound Swab & & 105 & 91.30 \\
\& Pus & 115 & 71 & 59.17 \\
Urine & 120 & 176 & 74.89 \\
Total & 235 & & \\
\hline
\end{tabular}

Table-II shows among the 176 isolates 150(85.23\%) were gram-negative bacteria, of which majority were E. coli $70(39.77 \%)$, followed by Klebsiella spp. 40(22.73\%), Pseudomonas spp. 25(14.21\%), Proteus spp. 12(06.82\%) \& Acinetobacter spp. 03(1.70\%) and 26(14.77\%) were grampositive bacteria, of which Staphylococcus aureus 18(10.23\%), Enterococci spp. 05(2.84\%) \& Coagulase negative staphylocci were $03(1.70 \%)$.

Table II : Distribution of bacterial isolates $(\mathrm{n}=176)$.

\begin{tabular}{|c|c|c|c|}
\hline Name of bacterial species & $\begin{array}{l}\text { Wound swab } \\
\text { \& pus } \\
(\mathrm{n}=105)\end{array}$ & $\begin{array}{l}\text { Urine } \\
(n=71)\end{array}$ & $\begin{array}{c}\text { Total number } \\
\text { of bacteria } \\
(n=176)\end{array}$ \\
\hline E. coli & $25(23.81)$ & $45(63.38)$ & $70(39.77)$ \\
\hline Klebsiella species & $26(24.76)$ & $14(19.72)$ & $40(22.73)$ \\
\hline Pseudomonas species & $23(21.90)$ & $02(02.82)$ & $25(14.21)$ \\
\hline Proteus species & $10(09.52)$ & $02(02.82)$ & $12(06.82)$ \\
\hline Acinetobacter species & $00(00.00)$ & $03(4.22)$ & $03(01.70)$ \\
\hline Total gram-negative bacteria & a $84(80.00)$ & $66(92.96)$ & $150(85.23)$ \\
\hline Staphylococcus aureus & $18(17.14)$ & $00(00.00)$ & $18(10.23)$ \\
\hline Enterococci species & $00(00.00)$ & $05(7.04)$ & $05(02.84)$ \\
\hline \multicolumn{4}{|l|}{ Coagulase negative } \\
\hline staphylococci & $03(2.86)$ & $00(00.00)$ & $03(01.70)$ \\
\hline Total gram positive bacteria & $21(20.00)$ & $05(7.04)$ & $26(14.77)$ \\
\hline
\end{tabular}

It appears total 150 isolated gram-negative bacteria were screened for suspected ESBLs producers on the basis of MIC ESBL breakpoints, out of which 142 (94.67\%) were found suspected ESBLs producers \& $8(5.33 \%)$ gave negative result (Figure-3).

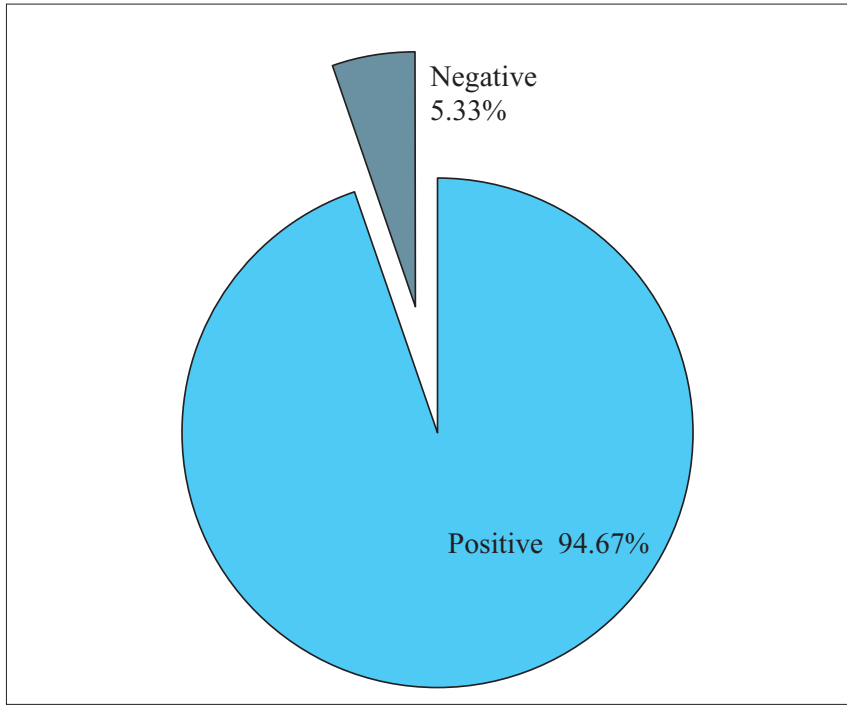

Figure 3 : Detection of ESBL producing bacteria on the basis of MIC (Screening test) by agar-dilution method.

Screening positive 142 suspected ESBLs producing bacteria were subjected to double disc synergy test, it was found $74(52.11 \%)$ were positive \& 68(47.89\%) were double disc synergy test negative (Figure 4).

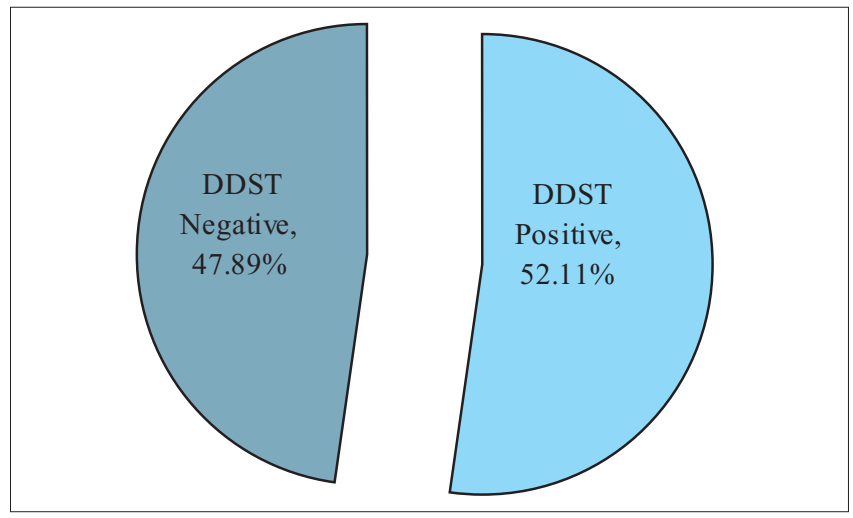

Figure 4 : Detection of ESBL producing organisms by double disc synergy test.

142 suspected ESBLs producing bacteria were further tested by phenotypic confirmatory test where $89(62.68 \%)$ found as confirmed ESBL producers \& 53(37.32\%) showed negative result (Figure 5).

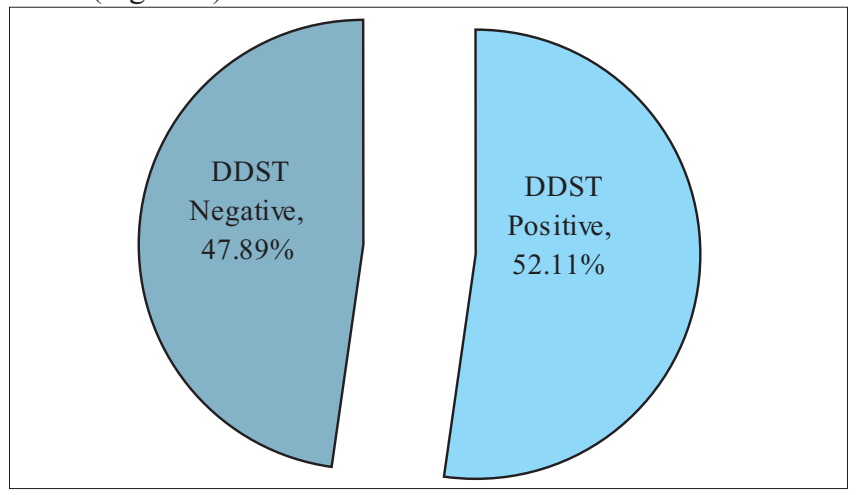

Figure 5 : Detection of ESBL producing organisms by phenotypic confirmatory test. 
Table 3 shows comparison of ESBLs positive isolates by double disc synergy test and phenotypic confirmatory test. 5 strains of E. coli, 5 strains of Klebsiella species, 2 strains of Pseudomonas species, 2 strains of Proteus species, 1 strains of Acinetobacter species shows positive reaction by phenotypic confirmatory test but negative result by double disc synergy test.

No strain was found double disc synergy test positive but phenotypic confirmatory test negative. Total $15(10.56 \%)$ isolates were missed by double disc synergy test. The difference in ESBLs detection by double disc synergy test and phenotypic confirmatory test were statistically very highly significant $(\mathrm{p}<0.001)$.

Table 3 : Comparison between Phenotypic Confirmatory Test (PCT) \& Double Disc Synergy Test (DDST) on detection of ESBLs producers $(n=142)$.

\begin{tabular}{lrrrr}
$\begin{array}{l}\text { Name of } \\
\text { strains tested }\end{array}$ & $\begin{array}{c}\text { Phenotypic } \\
\text { confirmatory } \\
\text { test positive }\end{array}$ & $\begin{array}{c}\text { Double disc } \\
\text { synergy } \\
\text { test positive }\end{array}$ & $\begin{array}{c}\text { PCT }(+) \text { ve } \\
\text { DDST }(-) \text { ve }\end{array}$ & $\begin{array}{c}\text { PCT }(-) \text { ve } \\
\text { DDST }(+) \text { ve }\end{array}$ \\
$\begin{array}{l}\text { E. coli } \\
(\mathrm{n}=65)\end{array}$ & $41(63.08)$ & $36(55.38)$ & $05(07.69)$ & $00(00.00)$ \\
$\begin{array}{l}\text { Klebsiella spp. } \\
(\mathrm{n}=37)\end{array}$ & $27(72.97)$ & $22(59.46)$ & $05(13.51)$ & $00(00.00)$ \\
$\begin{array}{l}\text { Pseudomonas } \\
\text { spp. }(\mathrm{n}=25)\end{array}$ & $13(52.00)$ & $11(44.00)$ & $02(08.00)$ & $00(00.00)$ \\
$\begin{array}{l}\text { Proteus spp. } \\
(\mathrm{n}=12)\end{array}$ & $07(58.33)$ & $05(41.67)$ & $02(16.67)$ & $00(00.00)$ \\
$\begin{array}{l}\text { Acinetobacter } \\
\text { spp. }(\mathrm{n}=03)\end{array}$ & $01(33.33)$ & $00(00.00)$ & $01(33.33)$ & $00(00.00)$ \\
Total (n=142) & $* 89(62.68)$ & $* 74(52.11)$ & $15(10.56)$ & $00(00.00)$ \\
\hline
\end{tabular}

- Figures within parentheses indicate percentages

$* \chi^{2}=88.721 ; \mathrm{p}<0.001$. Very highly significant

In this study, sensitivity, specificity, positive predictive value \& negative predictive value of phenotypic confirmatory test in comparison to double disc synergy test were $100 \%, 77.9 \%$, $83.1 \%$ \& $100 \%$ respectively (Table 4 ).

Table 4 : Sensitivity, specificity, positive \& negative predictive value of double disc synergy test and phenotypic confirmatory test.

$\begin{array}{lcc}\text { Double Disc } & \begin{array}{c}\text { Phenotypic } \\ \text { Synergy Test } \\ \text { (DDST) }\end{array} & \begin{array}{c}\text { Confirmatory } \\ \text { test (PCT) }\end{array} \\ \text { Sensitivity } & 83.1 \% & 100.0 \% \\ \text { Specificity } & 100.0 \% & 77.9 \% \\ \text { Positive predictive value } & 100.0 \% & 83.1 \% \\ \text { Negative predictive value } & 77.9 \% & 100.0 \%\end{array}$

\section{DISCUSSION}

In the present study, a total of 235 samples were collected and of which 115 were wound swab \& pus, and 120 were urine samples. From these samples, culture positive bacterial isolates were $176(74.89 \%)$ and among which $105(91.30 \%)$ from wound swab \& pus, and 71(59.17\%) from urine samples. This result is closely related to that of Rahman in Bangabandhu Sheikh Mujib Medical University (BSMMU) Dhaka, who found $69.41 \%$ culture positive isolates and isolated $93.92 \%$ organisms were from wound swab \& pus, and $53.57 \%$ from urine samples ${ }^{10}$.

Among the bacterial isolates, 150(85.23\%) were gram-negative and 26(14.77\%) were gram-positive in our study (Table 2). Similar to present study Alim and Rahman of BSMMU, Dhaka found $90.21 \%$ gram-negative \& $9.79 \%$ gram-positive and $90 \%$ gram-negative \& $10 \%$ gram-positive isolates respectively ${ }^{10,11}$. Amongst the isolates in our study, the majority were E. coli $70(39.77 \%)$, followed by Klebsiella spp. 40(22.73\%), Pseudomonas spp. 25(14.21\%), Staphylococcus aureus 18(10.23\%), Proteus spp. 12(06.82\%), Enterococci spp. 5(2.84\%), Acinetobacter spp. 3(1.70\%) and Coagulase-negative staphylococci 3(1.70\%). Similarly, Haq et al. of Dhaka showed E. coli $(37.10 \%)$ and Klebsiella spp. $(17.60 \%)$ as the most prevalent isolates from the clinical samples in a multi-center study, in Bangladesh. In contrast to our findings Rahman revealed E. coil $(40.63 \%)$ \& Proteus spp. (18.44\%) and Alim revealed E. coli (42.39\%) \& Pseudomonas spp. (22.28\%) as the prevalent isolates in their study ${ }^{10,11}$. These sorts of variation are not unexpected, because it depends upon some external factors like socioeconomic conditions, hygienic status, environmental factors, level of education, and genetic factors $^{12}$.

In the present study, we found 142(94.67\%) suspected ESBLs producers from 150 gram-negative isolates, based on Minimum Inhibitory Concentration (MIC) ESBLs screening breakpoints (Figure 3). As using more than one antibiotic increase the sensitivity, we used three third generation cephalosporins (Ceftriaxone, ceftazidime \& cefotaxime) for the screening ${ }^{8}$. Our finding is closely related to that of Metri et al in North Karnataka, India, who found $91.74 \%$ suspected ESBLs producers by screening test. ${ }^{1}$

74(52.11\%) by Double Disc Synergy Test (DDST).

When these 142 screening positive isolates were subjected to the confirmatory tests, $74(52.11 \%)$ were confirmed as ESBL producers by Double Disc Synergy Test (DDST) (Figure 4) and $89(62.68 \%$ ) by Phenotypic Confirmatory Test (PCT) (Figure 5). Closely similar to the present study, Dalela (2012) of Rajasthan, India detected ESBL producers $61.6 \%$ by PCT \& $57.5 \%$ by DDST and Giriyapur et al (2011) of Karnataka, India detected $63.89 \%$ by PCT \& $56.23 \% \operatorname{DDST}^{13,14}$. 
Comparison of ESBLs positive isolates by double disc synergy test and phenotypic confirmatory test (Table 3) showed that $15(10.56 \%)$ isolates were missed by double disc synergy test. $7.69 \%$ of E. coli, $13.51 \%$ of Klebsiella species, $8 \%$ of Pseudomonas species, $16.67 \%$ of Proteus species and $33.33 \%$ of Acinetobacter species showed positive reaction by phenotypic confirmatory test but negative result by double disc synergy test. No strain was found double disc synergy test positive but phenotypic confirmatory test negative. The difference in ESBLs detection by double disc synergy test and phenotypic confirmatory test were statistically very highly significant $(\mathrm{p}<0.001)$.

The double disc synergy test lacks sensitivity because of the problem of optimal disc spacing, need of precision, correct storage of the clavulanate containing discs, inability of the clavulanate to inhibit all ESBLs and the inability of the test to detect ESBLs in strains producing chromosomal cephalosporinases $^{1,15}$.

In present study, we found sensitivity, specificity, positive predictive value \& negative predictive value of PCT are $100 \%$, $77.9 \%, 83.1 \%$ \& $100 \%$ respectively and those of DDST are $83.1 \%, 100 \%, 100 \%$ \& $77.9 \%$ respectively (Table 4). Similarly, Giriyapur et al. (2011) of Karnataka, found sensitivity, specificity, positive predictive value and negative predictive value of DDST were $94.89 \%, 75.91 \%, 83.55 \%$ \& $92.03 \%$ respectively ${ }^{14}$. Of the two tests, used in the study, phenotypic confirmatory test found to be more sensitive procedure than double disc synergy test for the detection of ESBLs producing organisms. Similar findings were also reported by some other studies $1,16,17,18$. For this reason, some authors recommended phenotypic confirmatory test for the detection of ESBLs producers ${ }^{14,18,19}$.

\section{CONCLUSION}

Existing of extended spectrum -lactameses in bacteria and their potential multidrug resistance will create serious problem in the future as their continuous mutation and limited therapeutic option. Indiscriminate use of antibiotics especially $3^{\text {rd }}$ generation cephalosporins and monobactams should be avoided. The regular detection of ESBLs producing organisms by conventional methods should be carried out in every laboratory where molecular methods cannot be performed.

\section{DISCLOSURE}

All the authors declared no competing interest. 


\section{REFERENCES}

1. Metri BC, Jyothi P, Peerapur BV. The prevalence of ESBL among Enterobaceriaceae in a tertiary care hospital of North Karnataka, India. J of Clinical and Diagnostic Research. 2011; 5(3): 470-445.

2. Al-Jasser AM. Extended-Spectrum $\beta$-Lactamases (ESBLs): A global problem. Kuwait Med J. 2006; 38: 171-185

3. Livermore DM. $\beta$-Lactamases in laboratory and clinical resistance. Clinical Microbiology Reviews. 1995; 8(4): 557-584.

4. Samaha-Kfoury JN, Araj GF. Recent development in $\beta$-lactamases and extended-spectrum $\beta$-Lactamases. BMJ. 2003; 327: 1209-1213.

5. Paterson DL, Bonomo RA. Extended-spectrum B-Lactamases: A clinical update', Clinical Microbiology Reviews. 2005; 18(4):657-686.

6. Bradford PA. Extended-spectrum $\beta$-Lactamases in the $21^{\text {st }}$ century: Characterization, epidemiology, and detection of this important resistant threat. Clinical Microbiology Reviews. 2001; 14(4), 933-951.

7. Sobel JD, Kaye D. Urinary Tract Infections in GL Mandell, JE Bennett \& R Dolin (Eds), Mandell, Doglus and Bennett's principles and practice of infectious diseases, Churchill Livingstone, Philadelphia. 2010;7: 957-985.

8. Clinical and Laboratory Standards Institute. Performance standards for antimicrobial susceptibility testing, seventeenth informational supplement. CLSI Document M100-S17, Wayne, Pennsylvania, USA. 2007; 27(1): 1-177.

9. Jarlier V, Nicolas MH, Fournier G \& Philippon A. Extended broad-spectrum beta-lactamases conferring transferable resistance to newer betalactam agents in Enterobacteriaceae: Hospital prevalence and susceptibility patterns. Rev Infect Dis. 1988; 10(4): 867-878.

10. Rahman M. Rapid detection of extended-spectrum $\beta$-lactamases production directly from primary culture. M. Phil. Thesis, Bangabandhu Sheikh Mujib Medical University, Dhaka. 2007.

11. Alim R. Detection of Extended-Spectrum- $\beta$-Lactamases (ESBLs) producing bacteria. M. Phil. Thesis, Bangabandhu Sheikh Mujib Medical University, Dhaka. 2005.

12. Neely AN, Maley MP. Survival of Enterococci and Staphylococci on hospital fabrics and plastic. J of Clinical Microbiology. 2000; 38(2): 724-726.

13. Dalela G. Prevalence of Extended Spectrum Beta-Lactamase (ESBL) producers among gram negative bacilli from various clinical isolates in a tertiary care hospital at Jhalawar, Rajasthan, India. J of Clinical and Diagnostic Research. 20126; 2: 182-187.

14. Giriyapur RS, Nandihal NW, Krishna BV, Patil AB, Chandrasekhar MR. Comparison of disc diffusion methods for the detection of extended spectrum beta lactamase producing Enterobacteriaceae. J of Laboratory Physicians. 2011; 3(1): 33-36, viewed on 25 October 2011, http://www.jlponline.org.

15. Jabeen K, Zafar A \& Hasan R. Comparison of double disc and combined disc method for the detection of extended spectrum $\beta$-lactamases in Enterobacteriaceae. J of Pakistan Medical Association. 2003; 53(11): 534-536.

16. Umadevi S, Kandhakumari G, Joseph NM, Kumar S, Easow JM, Stephen S \& Singh UK. Prevalence and antimicrobial susceptibility pattern of ESBL producing gram-negative bacilli. J of Clinical and Diagnostic Research. 2011; 5(2): 236-239.

17. Svard L. Evaluation of phenotypic and genotypic extended spectrum beta-lactamases detection method. School of Biological Sciences. Dublin Institute of Technology. 2007; 1-77.

18. Khan MKR, Thukral SS \& Gaind R. Evaluation of modified double disc synergy test for the detection of extended spectrum -lactamases in AMPC in $\beta$-Lactamase-producing Proteus mirabilis. Indian J of Medical Microbiology. 2008; 26(1): 58-61, viewed on 24 June 2008, http://www.ijmm.org/article.asp?issn=0255-0857

19. Ahamed K, Thokar MA, Toboli AS, Fomda BA, Bashir G, Maroof P. Extended spectrum- $\beta$-Lactamase mediated resistance in Escherichia coli in a tertiary care hospital in Kashmir, India. African J of Microbiology Rasearch. 2010; 4(24): 2720-2728. 